\title{
Study on the influence of track conditions on dynamic wheel load variation
}

\author{
Y. Kawasaki ${ }^{1}$, M. Miwa ${ }^{1} \&$ A. Yoshimura ${ }^{2}$ \\ ${ }^{1}$ Technology Research \& Development Department, \\ General technology Division, Central Japan Railway Company, Japan \\ ${ }^{2}$ School of Computer Science, Tokyo University of Technology, Japan
}

\begin{abstract}
This paper presents our achievements for the deeper understanding of the vehicle-track dynamic interactions. First we have developed "TRADYS" (Track \& Structural Dynamics Simulator), which is the testing instrument to excite a certain fixed point on the test track to produce the vehicle-track dynamic interaction similar to that actually produced by the passing trains on the commercial lines. We have also established the numerical simulation model of the vehicle-track dynamics of TRADYS. Through the combination of the above two experimental and theoretical approaches, we analyzed the influence of the track conditions on the wheel load variation. In this study, we took into account the four example track conditions for the test and the simulation, where the assumptions were as follows: (1) Standard track condition of Tokaido Shinkansen, (2) Instalment of less elastic rail pads instead of standard rail pads, (3) Instalment of resilient sleepers instead of standard sleepers (4) Both above replacements (2) and (3). The vehicle specifications of the Series 700 of Tokaido Shinkansen with the speed at $270 \mathrm{~km} / \mathrm{h}$ were chosen and used in this analysis. As a result, we obtained the following outcomes: (1) In the frequency ranges of up to $50 \mathrm{~Hz}$, the replacement of both/either the rail pads and/or the sleepers resulted in no reductive influence on the wheel load variation. (2) On the other hand, in the frequency ranges of over $50 \mathrm{~Hz}$, the replacement of both/either the rail pads and/or the sleepers contributed to the reduction of wheel load variation. (3) In the frequency ranges of over $50 \mathrm{~Hz}$, the lower track support spring led to the weaker transmissibility ratio of a track (irregularity) to wheel load variation.
\end{abstract}

Keywords: wheel load variation, excitation test, computer simulation. 


\section{Introduction}

For the deeper understanding of the vehicle-track dynamic interactions, we have developed the test facility "TRADYS" (Track \& Structural Dynamic Simulator) [1] and established the numerical simulation model of the vehicle-track dynamics of TRADYS [2]. The advantages of coupling TRADYS and the numerical simulation model are that quite a few cases can be simulated just by instantly changing the track conditions or the vehicle conditions, and that the consistency of test results and simulation results can easily be justified.

In this paper, by means of combining TRADYS and the numerical simulation mode, the fix-point excitation tests results were compared with the simulation results under various track conditions, through which we pursued the influence of track conditions on dynamic wheel load variation.

\section{Excitation tests at fixed point under various track conditions}

For the excitation tests at fixed point to investigate the influence of various track conditions on wheel load variation, we altered the spring constant of the railpads and/or replaced the concrete sleepers with resilient sleepers.

\subsection{Summary of tests}

The tests were carried out using dynamics testing bogie of TRADYS (Figure 1) in the test line in Komaki research facility of JR Central. The same bogie as is installed in the Series 700 Tokaido Shinkansen trainsets was remodelled and used as the vibration exciter in this test, and the bogie was equipped with an unsprung mass that consisted of hydraulic actuators and weights where one of the wheelsets had been removed. The weight of the unsprung mass could be altered by adjusting the weight of steel plates. In the tests, the excitation force required to realize the predetermined compulsory displacement between the wheel and the rail was measured by controlling the actuators, which was regarded as the wheel load variation.

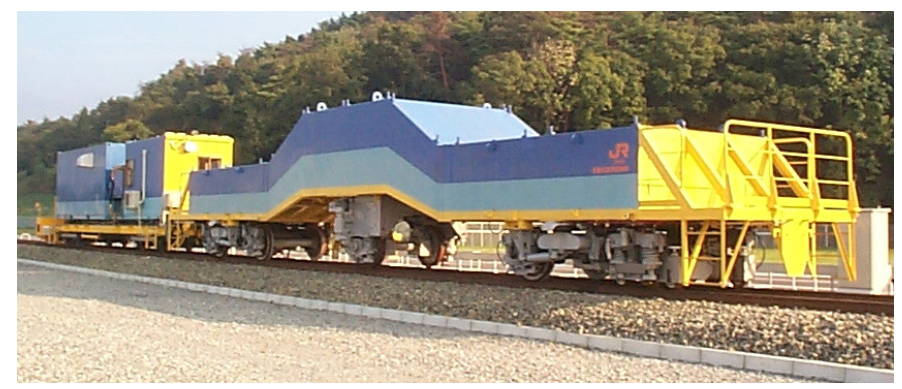

Figure 1: $\quad$ Track and Structural Dynamic Simulator, TRADYS. 
The track structure of the test line in the research facility is just the same as the standard track structure of Tokaido Shinkansen, where JIS $60 \mathrm{~kg}$ rail and JIS 102 type rail fastening system (railpad thickness: $12 \mathrm{~mm}$ ) are installed with the sleepers spacing of $581 \mathrm{~mm}$ and with the ballast thickness of $300 \mathrm{~mm}$ beneath the sleeper bottom.

\subsection{Test conditions}

The test conditions of the excitation tests at fixed point are shown in Table 1. As the spring constant of the railpads, $50 \mathrm{MN} / \mathrm{m}$ (standard type of Tokaido Shinkansen, made of SBR) and 30MN/m (low elastic type, made of PUR) were chosen. As the type of the sleepers, 4T (standard sleeper type of Tokaido Shinkansen) and the resilient sleeper type of Tokaido Shinkansen (hereafter shown as "4TE") were selected. Then the four test conditions were determined combining two railpad types and two sleeper types.

The excitation wave was given in the form of compulsory displacement, taking into account the values of the track irregularity and the rail roughness that had been measured by actual track inspection cars. The wavelength involved in this excitation ranged from $0.2 \mathrm{~m}$ to $150 \mathrm{~m}$, and the train speed was assumed to be $270 \mathrm{~km} / \mathrm{h}$. The unsprung mass of TRADYS was set as $1.8 \mathrm{tf}$.

Table 1: $\quad$ Test conditions.

\begin{tabular}{|c|c|c|}
\hline Test condition & $\begin{array}{c}\text { Spring constant of } \\
\text { railpad }\end{array}$ & Sleeper \\
\hline No. 1 & $50 \mathrm{MN} / \mathrm{m}$ & \multirow{2}{*}{$4 \mathrm{~T}$} \\
\hline No. 2 & $30 \mathrm{MN} / \mathrm{m}$ & \\
\hline No.3 & $50 \mathrm{MN} / \mathrm{m}$ & \multirow{2}{*}{$4 \mathrm{TE}$} \\
\hline No.4 & $30 \mathrm{MN} / \mathrm{m}$ & \\
\hline
\end{tabular}

\subsection{Results}

The power spectrum density of excitation wave given in the excitation tests is shown in Figure 2. The comparisons of the power spectrum densities of the excitation force by dynamics testing bogie (equivalent to wheel load variation) are shown in Figure 3 and 4 . Note that the obtained power spectrum density in the frequency range over $60 \mathrm{~Hz}$ might not be necessarily accurate since the measured excitation force is expected to be smaller than the real one due to the characteristic of the load cell used [2].

In Figure 3, it can be seen that the power spectrum densities of excitation force are quite similar in the cases of $50 \mathrm{MN} / \mathrm{m}$ and $30 \mathrm{MN} / \mathrm{m}$ of railpads. On the other hand, in Figure 4, it can be seen that the power spectrum densities of excitation force are quite similar under $40 \mathrm{~Hz}$ in the cases of $4 \mathrm{TE}$ sleeper and $4 \mathrm{~T}$ sleeper; however the power spectrum density in the case of 4TE sleeper becomes smaller over $40 \mathrm{~Hz}$. Therefore, it can be said that a resilient sleeper is effective for reducing wheel load variation over $40 \mathrm{~Hz}$, and that resilient sleepers and low elastic railpads are not effective for this purpose under $40 \mathrm{~Hz}$. 


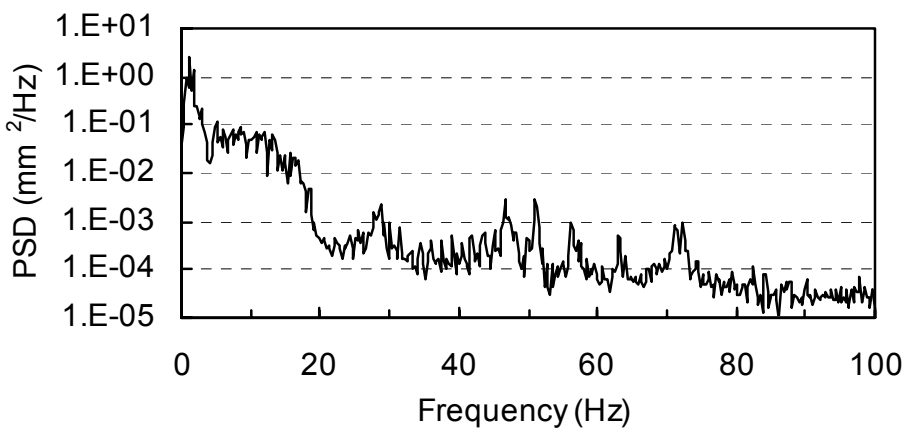

Figure 2: $\quad$ Power spectrum density of excitation wave.

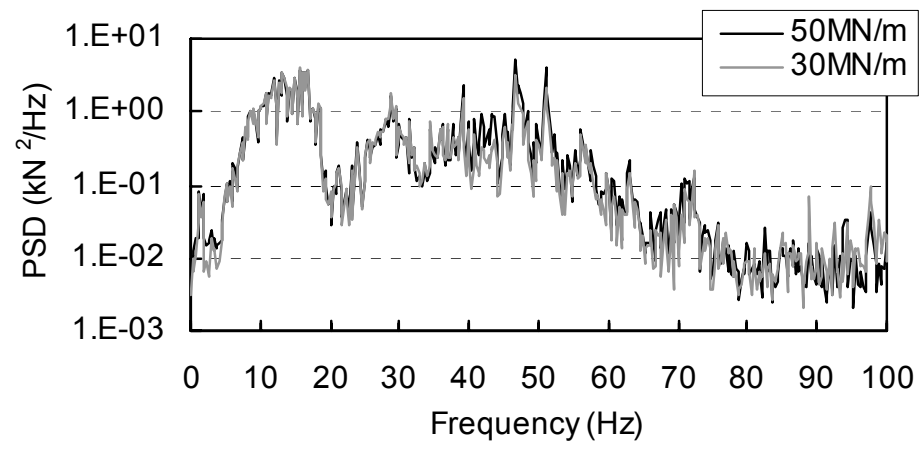

(a) Comparison of PSD between No.1 with No.2 (4T sleeper)

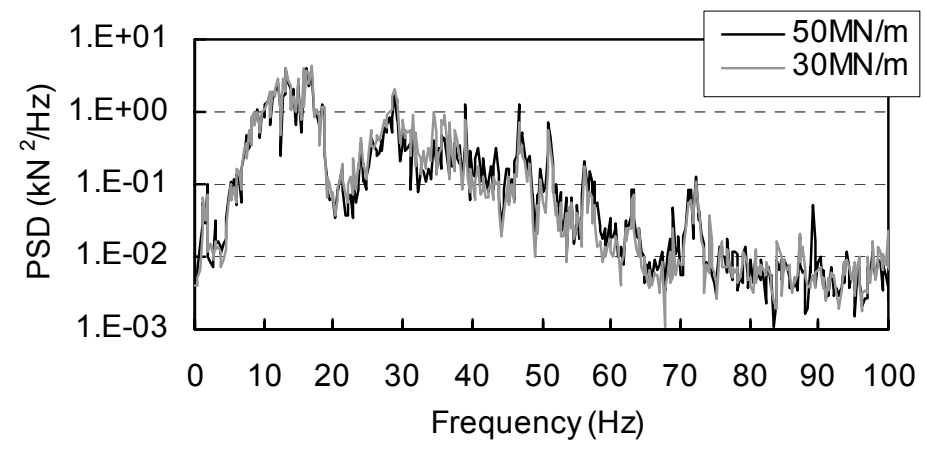

(b) Comparison of PSD between No.3 with No.4 (4TE sleeper)

Figure 3: $\quad$ Power spectrum densities of excitation force (wheel load variation) for different spring constant of rail pads. 


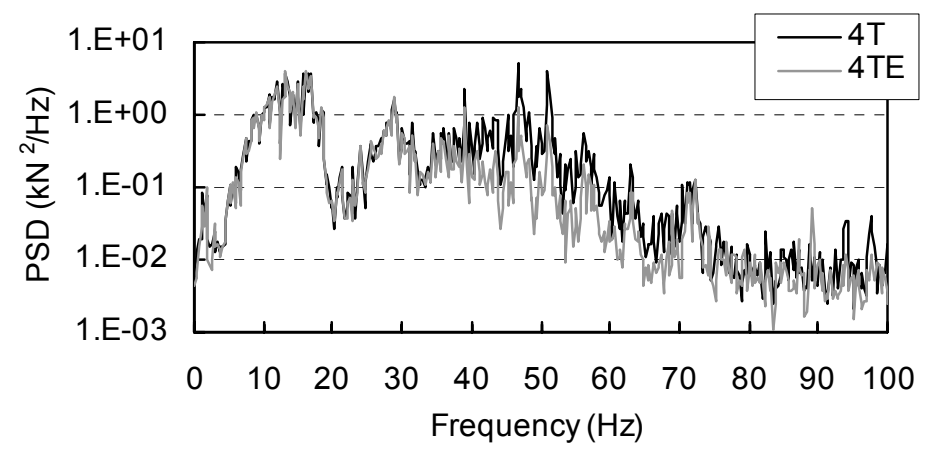

(a) Comparison of PSD between No.1 with No.3 (50MN/m railpads)

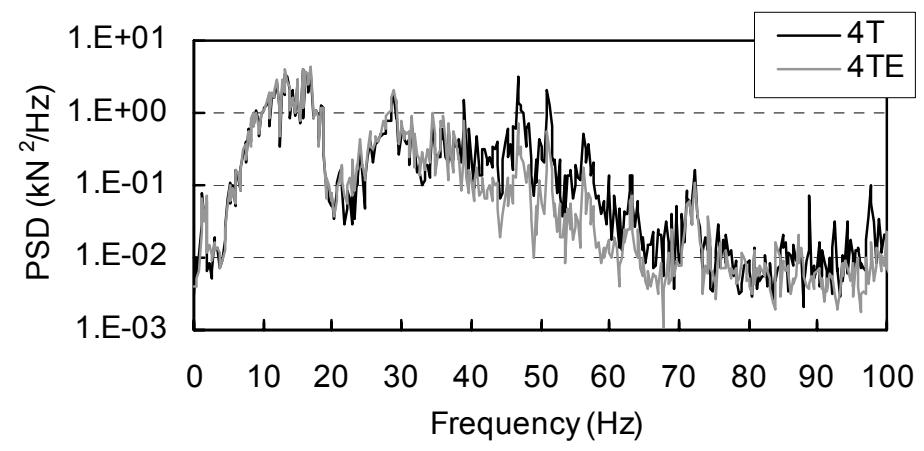

(b) Comparison of PSD between No.2 with No.4 (30MN/m railpad)

Figure 4: $\quad$ Power spectrum densities of excitation force (wheel load variation) for different sleepers.

\section{Simulation of excitation test at fixed point}

The excitation tests at fixed point described in the previous chapter were simulated using numerical simulation program to investigate the influence of various track conditions on wheel load variation.

\subsection{Analysis model}

The numerical simulation model simulating the excitation tests at fixed point by means of TRADYS is shown in Figure 5.

The rail is assumed to be supported discretely on sleepers and thus, modelled as a beam consisting of finite elements. The sleeper is modelled as a point mass and the railpad is modelled as a linear spring and dumping element. The ballast parts are assumed to be as several layers (specifically three layers) with effective mass, each layer being connected by a linear spring and a dumping element. 
As shown in the figure, the vehicle model is assumed to consist of car body, bogie and wheelset as a half-body model, where each element is modelled as a point mass, being connected by a linear spring and a dumping element.

The detail on the mathematical method of this analysis model can be found elsewhere [2], thus omitted in this paper. The brief description is that the model of excitation test at fixed point by the compulsory displacement is represented by differential-algebraic equation (DAE), and the method of reducing the differential index is used for stable solution. The Newmark-Beta method is used for the numerical integration.

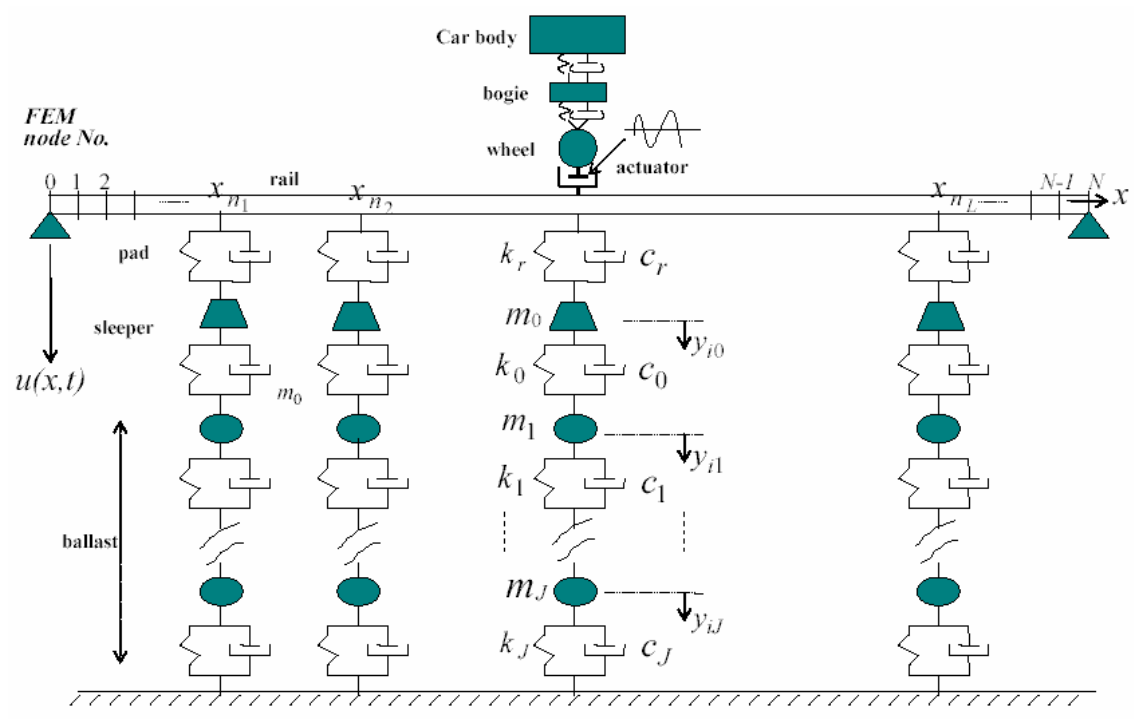

Figure 5: $\quad$ Mathematical simulation model of TRADYS test instrument.

\subsection{Analysis specifications}

The major specifications used in the numerical analysis of the excitation test at fixed point are shown in Table 2 .

Basically the specifications are the same as those described in Chapter 2; however, the spring constant of the railpads is assumed to be higher than the static spring constant considering the dynamic condition. The specifications of the vehicle are equivalent to those of Series 700 of Tokaido Shinkansen. Regarding the excitation wave, the same wave as was used in the test in the previous chapter is used in the numerical analysis, making it possible to compare the simulation results with the test results.

\subsection{Results}

The conditions assumed in the numerical simulation were same as those shown in Table 1 . The power spectrum density of wheel load variation obtained by the 
Table 2: $\quad$ Major analysis specifications.

\begin{tabular}{|c|c|c|}
\hline \multicolumn{2}{|c|}{ Item } & Value \\
\hline \multicolumn{2}{|c|}{ Contact spring between wheel and rail } & $1500 \mathrm{MN} / \mathrm{m}$ \\
\hline \multirow{2}{*}{ Rail } & Mass & $60.8 \mathrm{~kg} / \mathrm{m}$ \\
\hline & Bending rigidity & $6,435 \mathrm{kN} \cdot \mathrm{m}^{2}$ \\
\hline \multirow{9}{*}{ Ballast } & Mass (1st. layer) & $52.5 \mathrm{~kg}$ \\
\hline & Mass (2nd. layer) & $52.5 \mathrm{~kg}$ \\
\hline & Mass (3rd. layer) & $90.3 \mathrm{~kg}$ \\
\hline & $\begin{array}{c}\text { Spring constant } \\
\text { (Between 1st. and 2nd. layer) }\end{array}$ & $890 \mathrm{MN} / \mathrm{m}$ \\
\hline & $\begin{array}{c}\text { Dumping constant } \\
\text { (Between 1st. and 2nd. layer) }\end{array}$ & $980 \mathrm{kN} /(\mathrm{m} / \mathrm{s})$ \\
\hline & $\begin{array}{c}\text { Spring constant } \\
\text { (Between 2nd. and 3rd.layer) }\end{array}$ & $810 \mathrm{MN} / \mathrm{m}$ \\
\hline & $\begin{array}{c}\text { Dumping constant } \\
\text { (Between 2nd. and 3rd.layer) }\end{array}$ & $980 \mathrm{kN} /(\mathrm{m} / \mathrm{s})$ \\
\hline & $\begin{array}{c}\text { Spring constant } \\
\text { (Between 3rd. layer and roadbed) }\end{array}$ & $2,500 \mathrm{MN} / \mathrm{m}$ \\
\hline & $\begin{array}{c}\text { Dumping constant } \\
\text { (Between 3rd. layer and roadbed) }\end{array}$ & $980 \mathrm{kN} /(\mathrm{m} / \mathrm{s})$ \\
\hline \multirow{2}{*}{$\begin{array}{c}\text { Railpad } \\
(50 \mathrm{MN} / \mathrm{m})\end{array}$} & Spring constant & $80 \mathrm{MN} / \mathrm{m}$ \\
\hline & Dumping constant & $98 \mathrm{kN} /(\mathrm{m} / \mathrm{s})$ \\
\hline \multirow{2}{*}{$\begin{array}{c}\text { Railpad } \\
(30 \mathrm{MN} / \mathrm{m})\end{array}$} & Spring constant & $50 \mathrm{MN} / \mathrm{m}$ \\
\hline & Dumping constant & $98 \mathrm{kN} /(\mathrm{m} / \mathrm{s})$ \\
\hline \multirow{3}{*}{$\begin{array}{l}\text { Sleeper } \\
(4 \mathrm{~T})\end{array}$} & Mass & $129 \mathrm{~kg}$ \\
\hline & Spring constant & $1,780 \mathrm{MN} / \mathrm{m}$ \\
\hline & Dumping constant & $980 \mathrm{kN} /(\mathrm{m} / \mathrm{s})$ \\
\hline \multirow{3}{*}{$\begin{array}{l}\text { Sleeper } \\
(4 \mathrm{TE})\end{array}$} & Mass & $175 \mathrm{~kg}$ \\
\hline & Spring constant & $20 \mathrm{MN} / \mathrm{m}$ \\
\hline & Dumping constant & $980 \mathrm{kN} /(\mathrm{m} / \mathrm{s})$ \\
\hline
\end{tabular}

numerical simulation and the power spectrum density of the excitation force measured in the tests described in Chapter 2 are shown together in Figure 6.

In this figure, the power spectrum densities of the simulation result well accords with those of the test results under $30 \mathrm{~Hz}$ in all four track conditions. However over $30 \mathrm{~Hz}$, the differences in PSD seem to have trends to increase with higher frequency in all cases. These differences may be just attributable to the characteristic of the load cell using in the tests, and the numerical simulation is found to be of considerably good precision.

The transfer functions, the values of which are defined as the numerically obtained wheel load variation divided by the compulsory displacement, are shown in Figure 7. It can be seen that the transfer functions tend to decrease in the cases of railpads of low spring constant and resilient sleepers over $50 \mathrm{~Hz}$ frequency; however, the difference is almost negligible in the lower frequency. 


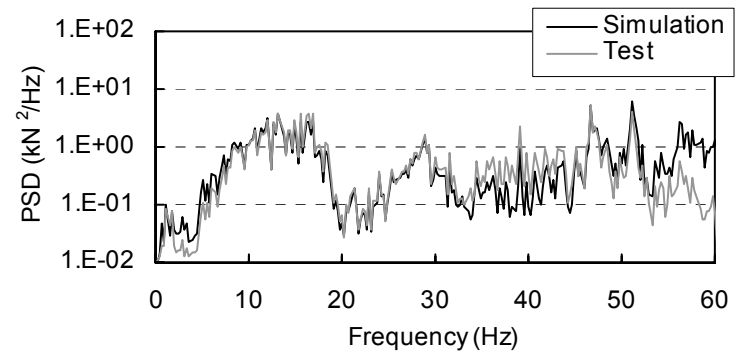

(a) Test condition No.1 (50MN/m pad, 4T sleeper)

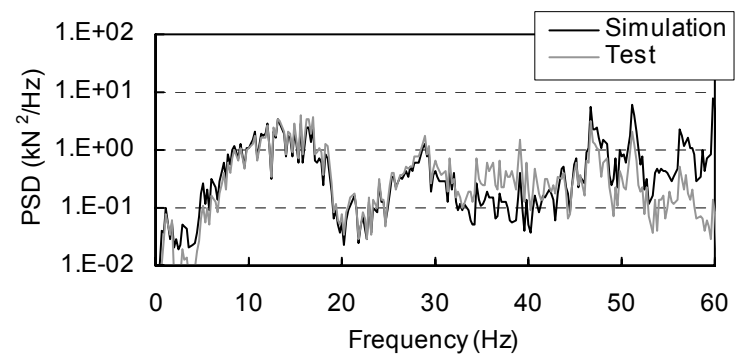

(b) Test condition No.2 (30MN/m pad, 4T sleeper)

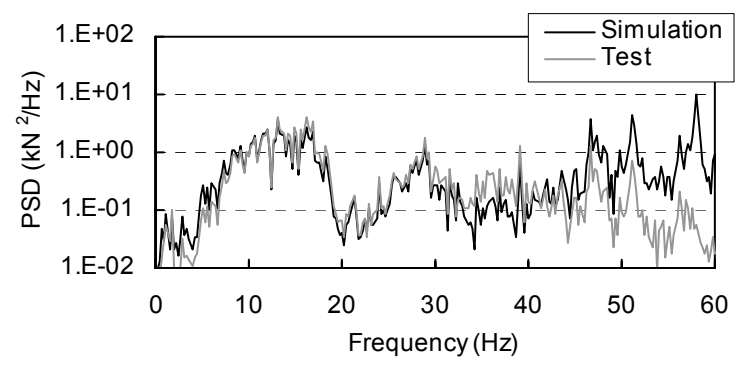

(c) Test condition No.3 (50MN/m pad, 4TE sleeper)

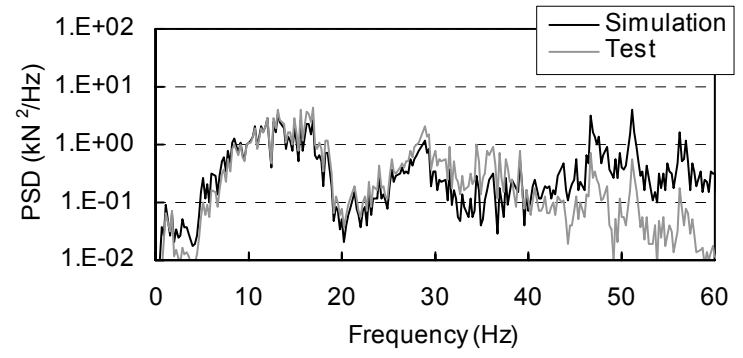

(d) Test condition No.4 (30MN/m pad, 4TE sleeper)

Figure 6: Power spectrum densities of wheel load variation (comparison between simulation results and test results). 
Therefore, it can be said that the lower spring constant dose not effectively contribute to the reduction of the wheel load variation in the low frequency.

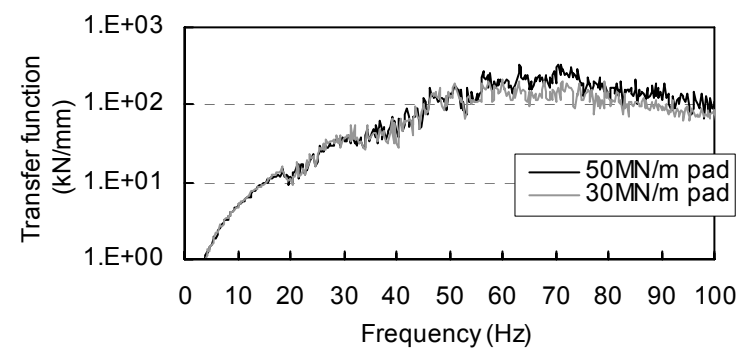

(a) Comparison between $50 \mathrm{MN} / \mathrm{m}$ pad and $30 \mathrm{MN} / \mathrm{m}$

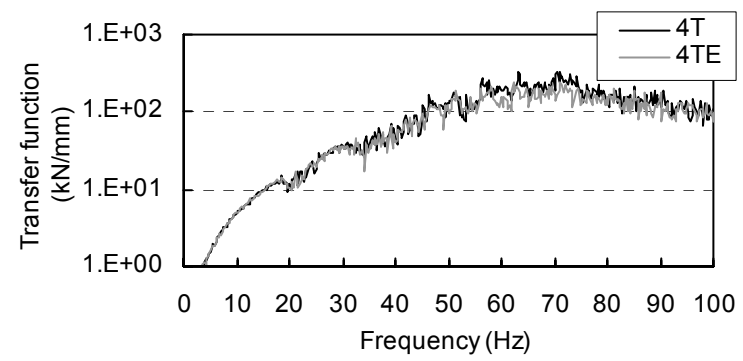

(b) Comparison between 4T sleeper and 4TE sleeper

Figure 7: Comparison of transfer functions calculated from simulation results.

\section{Conclusion}

The following conclusions can be derived by analyzing the test and the numerical results:

(1) In the frequency ranges of up to $50 \mathrm{~Hz}$, the replacement of both/either the railpads and/or the sleepers shows little reduction of wheel load variation.

(2) On the other hand, in the frequency ranges of over $50 \mathrm{~Hz}$, the replacement of both/either the railpads with the lower elastic ones and/or the sleepers with the resilient ones contributes to the reduction of wheel load variation.

(3) In the frequency ranges of over $50 \mathrm{~Hz}$, the lower track support spring leads to the weaker transmissibility ratio of a track (irregularity) to wheel load variation.

The approach method described in this paper is expected to be utilized in the further study on vehicle-track dynamic interactions in the future. 
672 Computers in Railways XI

\section{Reference}

[1] Miwa, M \& Nakamura, S., High speed running test and the new testing equipment for wheel/rail dynamic interaction, Proc. of Int. Symposium on Speed-up and Service Technology for Railway and Maglev Systems (STECH'03), JSME, pp.489-493, 2003

[2] M. Miwa \& A. Yoshimura, Study on vertical dynamic vehicle-track interactions using the TRADYS test facility and computer simulation, Computers in Railways X (COMPRAIL2006), pp.885-894, 2006 